\title{
A Method on Pressure Energy Recovery and Utilization of CNG
}

\author{
Automobile \\ Chao Xia ${ }^{1, a,{ }^{*}}$, Haisheng Chen ${ }^{1,2, b}$ and Xuehui Zhang ${ }^{1,2, c}$ \\ ${ }^{1}$ National Power Large Scale Physical Energy Technology (Bijie) R\&D Center, Bijie, \\ 551700, China \\ ${ }^{2}$ Institute of Engineering Thermophysics, Chinese Academy of Sciences, Beijing, \\ 100190, China \\ aCCAUC_xiachao@163.com, ${ }^{\mathrm{b}}$ chenhaisheng@iet.cn, 'chhangxuehui@iet.cn
}

\begin{abstract}
In order to improve energy efficiency and protect the environment, new energy vehicles have been developing vigorously. As one kind of the vehicles, CNG (Compressed Natural Gas) Automobiles and CNG \& Electric hybrid cars have been accelerating promotion. However, the current CNG vehicles are reducing the pressure of CNG through a reducing valve, so that achieves the intake gas pressure to the engines. Undoubtedly, it is a waste of the pressure energy for CNG. For utilizing of the pressure energy, this paper promotes a method that applies regenerative multi stage valve piston expanders to recycle the high pressure CNG energy power translated into electricity. It is estimated that the efficiency of the expander system under this technology is more than 55\%, the power storage and utilization efficiency is more than $90 \%$, and the overall CNG pressure energy recycling efficiency can reach more than $50 \%$.
\end{abstract}

Keywords: Compressed Natural Gas, pressure energy, multi stage valve piston expanders, recycle.

\section{Introduction}

In order to reduce transportation costs and increase the mileage of natural gas vehicles, CNG storage pressure is generally compressed to 20 35MPa, while the intake pressure requirement of CNG automotive engine is $0.2 \sim 0.3 \mathrm{MPa}^{[1]}$. For achieving the rated intake pressure of the engine, it applies a method to reduce pressure of the storage tank to the engines' intake pressure by using a reducing valve. The advantage of this method is simple structure and quickly decompressing.

However, this gas decompression technique has a following shortcoming: the valve in the step-down process compression caused a great degree of waste of natural gas pressure energy.

Recycling this part pressure energy of supply gas to improve the utilization efficiency of compressed natural gas energy, it adopts the design of regenerative multi-stage single valve piston expander and power generation technology. This application will 
convert the pressure energy into electrical energy, which consumed locally for gas automobiles' electricity.

\section{Method on Pressure Energy Recovery and Utilization of CNG Automobile}

\subsection{Overview of the Method}

According to the properties of CNG, the technique selects the corresponding number of multi-stage single valve piston expander, and then exchanges heating of compressed natural gas with high temperature tail gas from exhaust ternary catalytic converters of engine. It improves intake gas temperature of piston expanders and energy utilization rate. Because of the continuous CNG expenditure, the pressure within the gas tank in automobiles decreased constantly. Moreover, for different road conditions and other variable conditions, the engine intake flow is corresponded differently. It leads to the expansion of machine speed fluctuation. Afterwards, the generation power cannot be stable. Therefore, after the electricity power output, it must be stored in the DC storage battery for voltage and current stabilization in real-time ${ }^{[2-12]}$.

\subsection{Specific of Engineering Application Method}

It provides pressure energy recovery and utilization of a natural gas vehicle technology, designed by high pressure and small flow multistage single valve piston expander decreasing CNG pressure from $20 \sim 35 \mathrm{MPa}$ to $0.1 \sim 0.3 \mathrm{MPa}$ that engine available gas pressure.

In view of the CNG gas source pressure, according to the expansion ratio and the guarantee efficiency premise, it selects the 3 or more multistage single valve piston expanders as the reasonable system. The high temperature exhaust gas at $700{ }^{\circ} \mathrm{C}$ is guided into the heat exchangers after ternary catalyst, so that increasing temperature of the expanders' inlet gas to $300^{\circ} \mathrm{C}$ or more. When the compressed gas pumps the expansion machines, the expansion engine piston drives the transmission gearbox working, and then generator translates the energy to electricity. Finally, the electric energy is stored in the DC storage battery to be supplied to the vehicle in situ.

\section{Process of Application Method}

The vehicle (CNG-electric hybrid vehicle) engine's inlet gas system applied the recovery pressure energy technology is designed into two ${ }^{[1]}$ : the main path (applied of expanders' recovery pressure energy and generating system) and bypass path (applied of valve pressure). If there have some failures or other abnormal conditions happened in the main path, or the gas pressure inside the tank reaching to a certain limited pressure (cannot reached the start-up pressure expander system), the bypass pressure switch in main road will be cut off and then bypass path will be put into circulation, so that the remained compressed natural gas rapidly flows through the bypass into the automobile engine. As Figure 1 shows the expanded recovery pressure energy system applied in CNG automobiles. 


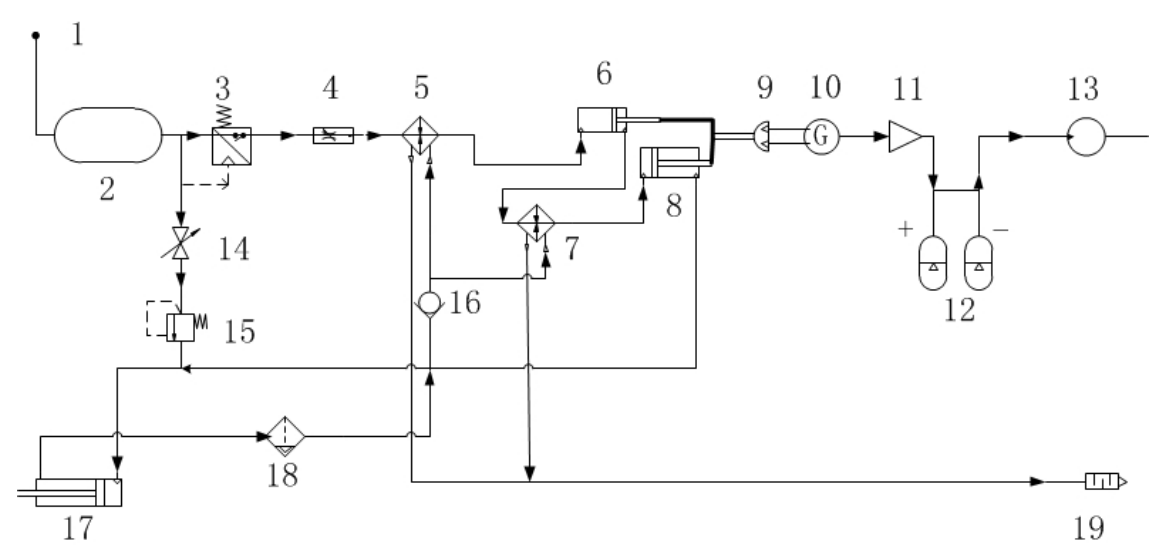

Fig. 1 Pressure energy recovery and utilization system of CNG automobile

Where : 1- filler neck; 2-CNG storage tank; 3- pressure switch; 4- intake valve; 5first stage heat exchanger; 6 - first stage single valve piston expander; 7- second stage heat exchanger; 8- second single valve piston expander; 9- gearing; 10- generator; 11inverter; 12- DC battery; 13- electric motor (hybrid vehicles); 14- electric valve; 15pressure-reducing valve; 16- check valve (such as engine exhaust to prevent reflux causing flameout); 17- CNG engine automobile catalytic converter; 18- ternary catalytic converter; 19- silencer. The remaining lines are gas paths.

The circulating primary process as follows:

1. CNG vehicles or CNG-Electric hybrid vehicles fill the CNG storage tank at the CNG filling station with 20MPa 35MPa gas.

2. According to the feedback signal of CNG flow engine under different working requirements, the work flow will be organized with control valve for a corresponding adjustment under different engine power, temperature and flow rate required.

3. A certain amount of CNG gas continues to flow into the heat exchangers. The exhaust gas at high temperature, derived from ternary catalytic converter as heat source. The high temperature heat source enters the primary heat exchanger, and the CNG gas is heated by heat exchange. Then heated CNG gas enters a first-stage single valve piston expander, the piston rod drives the transmission to move the reciprocating movement into axial rotation. After one expansion, the CNG gas continues to enter the next stage heat exchanger, and so on. The tail gas after heat transfer is discharged to the atmosphere through the silencer.

4. Expansion via gearing, actuating the generator to generate electricity stored in the DC storage battery group.

\section{Expansion work calculation}

The expansion of CNG gas in a piston expander can be regarded as an isentropic adiabatic process. The expansion work is related to the gas volume and the pre expansion pressure of the expanded gas. After the isentropic adiabatic expansion of $\mathrm{CNG}$, the temperature and pressure of the gas decrease, and the enthalpy change formula is calculated as follow formulates ${ }^{[6-9]}$ :

$$
T_{2}^{*}=T_{1} *\left(\frac{P_{2}}{P_{1}}\right)^{\frac{k-1}{k}}
$$




$$
\begin{gathered}
\mathrm{W}=-\mathrm{nRT} * \frac{k}{k-1} *\left[\left(\frac{p_{2}}{p_{1}}\right)^{\frac{k-1}{k}}-1\right] \\
\Delta \mathrm{H}=\mathrm{Q}+\mathrm{W}
\end{gathered}
$$

Where: k-adiabatic exponent, $\mathrm{P}_{1}$-primary gas pressure, $\mathrm{P}_{2}$-final gas pressure, $\mathrm{T}_{1}$-primary gas temperature, $\mathrm{T}_{2}$-final gas temperature, $\mathrm{Q}$-approximately zero, $\mathrm{W}$ expansion work, R- gas constant, n- molar quantity.

Hypotheses: pressure of storage CNG in vehicle tank is 20 35MPa, pressure of engine inlet gas is 0.1 0.3MPa. Estimations as follows:

\begin{tabular}{|c|c|c|c|c|c|}
\hline Type & Pressure & Temperature & Flow & Power & Efficiency \\
\hline Inlet & 20 35MPa & $576 \mathrm{~K}$ & $25 \sim 85 \mathrm{Nm}^{3} / \mathrm{h}$ & \multirow{2}{*}{$52 \sim 162 \mathrm{KW}$} & morn than \\
\hline Outlet & $0.1 \sim 0.6 \mathrm{MPa}$ & $198 K$ & - & & $50 \%$ \\
\hline
\end{tabular}

Table 1 Characteristics of primary inlet and final outlet gas

\section{Conclusions}

Pressure energy recovery and utilization technology, which mainly solves the technical problem that is to provide an improved natural gas vehicle energy utilization rate of gas, can effective recovery and utilization of CNG vehicle pressure energy, thereby improving the compressed natural gas vehicle energy utilization rate.

However, because of limited space, living weight loss and decreasing consumption, CNG automobiles energy recovery system according to this technology must be compact and concise. Therefore, how to combine the existing natural gas vehicle and the natural gas electric hybrid automobile engine system is a problem that needs to be solved further.

\section{Acknowledgments}

This work was financially supported by International S\&T Cooperation Program of China (No. 2014DFA60600) of National Natural Science Foundation fund.

\section{References}

[1] Wu Yudong. Supply system simulation and injection control of the CNG engine[D]. Xihua University, 2013(4).

[2] IBRAHIM H,YOUN S R, ILINCA A, et al. Potential of a Hybrid Wind-Diesel-Compressed air system for Nordic Remote Canadian Areas[J]. Energy Procedia, 2011, 6(0): 795-804.

[4] LEMOFOUET-GATSI S. Investigation and optimisation of hybrid electricity storage systems based on compressed air and supercapacitors[D]. Lausanne: Ecole Polytechnique Federale de Lausanne, 2006,

[5] Xue Haobai. Theoretical and Experimental Study of a Multistage Single Valve Reciprocating Expander [D]. Institute of Engineering Thermophysics Chinese Academy of Sciences, 2014(5). 
[6] KIM Y,SHIN D, FAVRAT D. Operating characteristics of constant-pressure compressed air energy storage (CAES) system combined with pumped hydro storage based on energy and exergy analysis[J]. Energy, 2011,36(10): 6220-6233.

[7] BASBOUS T,YOUNES R,ILINCA A,et al. Pneumatic hybridization of a diesel engine using compressed air storage for wind-diesel energy generation[J]. Energy, 2012,38(1): 264-275.

[8] CHEN H, DING Y,LI Y,et al. Air fuelled zero emission road transportation: A comparative study [J]. Applied Energy, 2011,88(1): 337-342.

[9] VAN DE VEN J D, LIPY. Liquid piston gas compression[J]. Applied Energy, 2009,86(10): 2183-2191.

[10]ZHANG X,XUE H,XU Y, et al. An investigation of an uninterruptible power supply (UPS) based on super capacitor and liquid nitrogen hybridization system[J], Energy conversion and management, (0).

[11]GRAZZINI G, M3LAZZO A. Thermodynamic analysis of CAES/TES systems for renewable energy plants[J]. Renewable Energy, 2008, 33(9): 1998-2006.

[12]GRAZZINI G,MILAZZO A. Exergy analysis of a CAES with thermal energy storage[C]/Proceedings of the 5th European Thermal-Sciences Conference. Eindhoven, 2008. 